University of Nebraska - Lincoln

DigitalCommons@University of Nebraska - Lincoln

Faculty Publications from the Department of Electrical \& Computer Engineering, Department Electrical and Computer Engineering

3-22-2005

\title{
Phase-graded deposition of diamond-like carbon on nanotips by near-field induced chemical vapor deposition
}

\author{
J. Shi \\ University of Nebraska-Lincoln \\ Yongfeng Lu \\ University of Nebraska-Lincoln, ylu2@unl.edu \\ X. Y. Chen \\ National University of Singapore \\ R. S. Cherukuri \\ University of Nebraska-Lincoln \\ K. K. Mendu \\ University of Nebraska-Lincoln \\ See next page for additional authors
}

Follow this and additional works at: https://digitalcommons.unl.edu/electricalengineeringfacpub

Part of the Electrical and Computer Engineering Commons

Shi, J.; Lu, Yongfeng; Chen, X. Y.; Cherukuri, R. S.; Mendu, K. K.; Wang, H.; and Batta, N., "Phase-graded deposition of diamond-like carbon on nanotips by near-field induced chemical vapor deposition" (2005). Faculty Publications from the Department of Electrical and Computer Engineering. 97.

https://digitalcommons.unl.edu/electricalengineeringfacpub/97

This Article is brought to you for free and open access by the Electrical \& Computer Engineering, Department of at DigitalCommons@University of Nebraska - Lincoln. It has been accepted for inclusion in Faculty Publications from the Department of Electrical and Computer Engineering by an authorized administrator of DigitalCommons@University of Nebraska - Lincoln. 


\section{Authors}

J. Shi, Yongfeng Lu, X. Y. Chen, R. S. Cherukuri, K. K. Mendu, H. Wang, and N. Batta 


\title{
Phase-graded deposition of diamond-like carbon on nanotips by near-field induced chemical vapor deposition
}

\author{
J. Shi and Y. F. Lu ${ }^{\text {a) }}$ \\ Department of Electrical Engineering, University of Nebraska-Lincoln, Lincoln, Nebraska 68588-0511 \\ X. Y. Chen \\ Department of Electrical and Computer Engineering, National University of Singapore, 10 Kent Ridge \\ Crescent, Singapore 119260
}

R. S. Cherukuri, K. K. Mendu, H. Wang, and N. Batta

Department of Electrical Engineering, University of Nebraska-Lincoln, Lincoln, Nebraska 68588-0511

(Received 5 January 2005; accepted 17 February 2005; published online 23 March 2005)

\begin{abstract}
Diamond-like carbon (DLC) films were deposited on tungsten (W) tips under the KrF excimer laser in a laser chemical vapor deposition (LCVD) chamber. Raman spectroscopy showed that the deposited DLC films were phase-graded along the tips from the apexes. The DLC films were more diamondlike at or near the tip apexes. From numerical simulation, there is a strongly confined and enhanced optical field at the tip apexes. The simulation also indicates that there is an optical-field gradient from tip apexes to tip bodies. Therefore, the variations in the phases of deposited DLC films were attributed to the corresponding variations in local optical intensities along the tips. Hence, optical local near field was confirmed to be responsible to the DLC deposition. () 2005 American Institute of Physics. [DOI: 10.1063/1.1887840]
\end{abstract}

Recently, optical near-field enhancement has been intensively studied due to its important applications in near-field optics and near-field nanostructuring. By irradiation of metallic spheres or sharp metal tips with lasers, strongly confined and enhanced fields can be obtained at or near the metallic spheres and tip apexes. The enhanced near-field becomes an energy source with extremely high spatial resolution and highly enhanced power intensity. Applications exploiting such advantages include scanning near-field optical microscope $(\mathrm{SNOM})^{1,2}$ and nanostructuring by laser-assisted scanning probe microscopy (SPM). ${ }^{3}$ However, use of optical near-field as the source for chemical vapor deposition (CVD) has not yet been investigated.

In traditional laser-assisted chemical reactions, such as laser-assisted deposition, etching and oxidation, lasers are used as an energy source responsible for photothermal as well as photolytic reactions. However, the spatial resolution is limited by the wavelength of the incident laser. Opticalnear-field-induced deposition (ONFID) has potentials for highly localized deposition of materials on specific structures, e.g. sharp tip, sharp edges, nanometer-sized particles, which are capable of generating locally-enhanced optical fields under proper laser irradiation. Since wavelength and temporal characteristics of the enhanced optical near field are the same as those of the incident laser, ${ }^{4}$ any established laser chemical reactions can also take place under the optical near field. One of the potential applications of ONFID technique is to deposit protective diamond and DLC films on sharp tips or gears in MEMS or NEMS devices for abrasive applications. Due to the local field enhancement, relatively low incident laser fluence is required for localized coating at tips and sharp edges. Therefore, the deposition is in a coldambient process, in which other parts can remain intact.

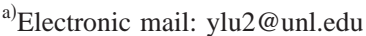

Our previous study ${ }^{5}$ demonstrated that tip sharpness directly affected the morphology and phase of the deposited DLC film on W tips immersed in a precursor solution at similar laser process conditions. Near-field effects were suggested to play important roles in the deposition process due to that the degree of field enhancement varied significantly for tips with different sharpness. However, direct evidence of near-field induced deposition was not obtained. In this study, we conducted laser deposition of DLC on a W tip in a LCVD system. Raman spectroscopy showed localized and phasegraded deposition of DLC films on a single tip, which helped to confirm that optical near-field effects played a dominant role in DLC deposition on sharp nanotips.

W tips were homemade using dc electrochemical etching of $\mathrm{W}$ wires $(0.25 \mathrm{~mm}$ in diameter $){ }^{6}$ In this study, laserassisted deposition was conducted in a laser chemical vapor deposition (LCVD) chamber. The experimental setup was shown in Fig. 1. A W tip was vertically attached to a sample holder. The chamber was first pumped to a base pressure of $1 \times 10^{-7}$ Torr and a steady benzene vapor around 3.6 Torr

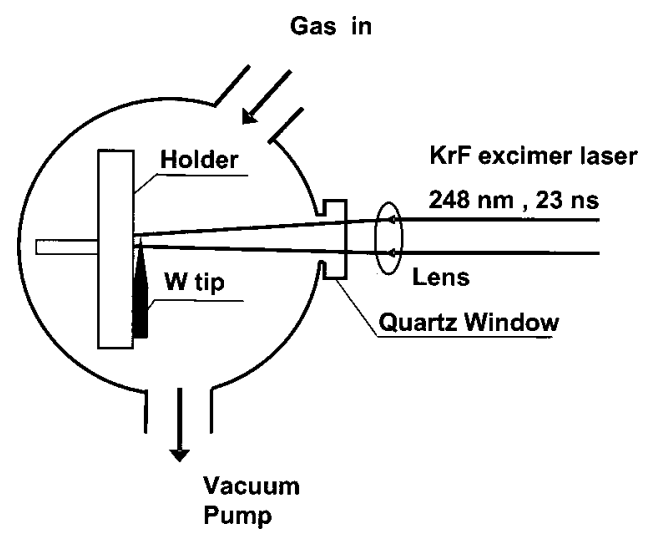

FIG. 1. Experiment setup of laser CVD system for DLC deposition on W tips. 

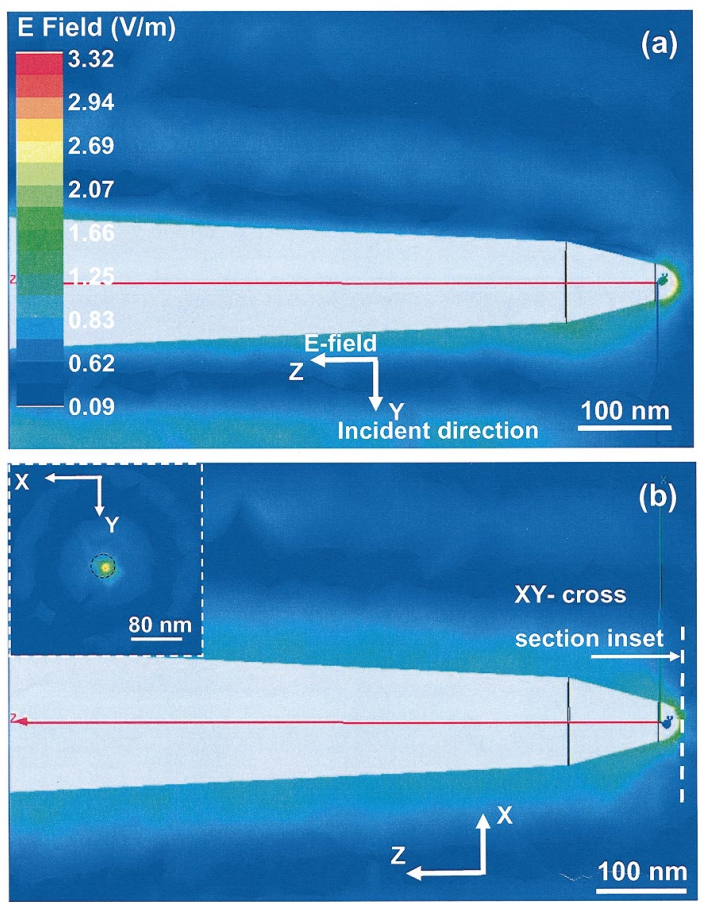

FIG. 2. (Color) Cross-sectional views of the simulated $E$-field distribution around the tip apex vicinity. The incident wave is along the $y$-axis, normal to the cone axis, with a magnitude of 1 ; the incident $E$-field is along the $z$-axis, parallel to the cone axis. The geometry of modeled tip is similar to what was used in the experiment. (a) $Z Y$ cross-sectional view of a tip with a curvature radius of $20 \mathrm{~nm}$. The inset is the $X Y$ cross-sectional view at the plane at the tip apex. (b) $Z X$ cross-sectional view of the same setup as (a).

was reached before laser irradiation. A $\mathrm{KrF}$ excimer laser (Lambda Physik Compex 205, wavelength $=248 \mathrm{~nm}$, pulse duration $=23 \mathrm{~ns}$ ) was used to irradiate the tip perpendicularly, with the beam size ranges from 20 to $40 \mathrm{~mm}^{2}$. Before each deposition, the apex of the tip was prealigned at the center of the laser beam. Compared with the size of the tip, we assumed that the laser beam was uniform at and near the tip apex. Morphological and structural characterizations were conducted by a Hitachi S-4700 field emission scanning electron microscope (FESEM) and a micro-Raman spectroscope excited by an argon ion laser at $514.5 \mathrm{~nm}$, respectively. In order to examine the possibility of structural variations along the tip, Raman spectra of various positions along the tip were examined. The argon ion laser used for micro-Raman spectroscope has a focused beam spot of $1 \mu \mathrm{m}$. High frequency structure simulator (HFSS v9.0, Ansoft Inc.) was used to simulate the optical field around the tip apexes. ${ }^{5}$

Figure 2 shows the cross-sectional views of the simulated $E$-field distribution around the tip apex vicinity using HFSS. The incident wave is along the $Y$-axis, perpendicular to the cone axis. The incident $E$-field is along the $Z$-axis, with a magnitude of 1 . The geometry of the tip in the simulation is modeled similar to what was used in the experiment, with a curvature radius of $20 \mathrm{~nm}$. In the $Y Z$ and $X Z$ crosssectional views, as shown in Figs. 2(a) and 2(b), the $E$-field distribution shows an optically-enhanced region surrounding the tip during the laser irradiation, with a maximum enhancement factor of 3.3 at the apex. The magnitude of the $E$-field decreases along the tip from the apex. The inset shown in Fig. 2(b) was an $X Y$ cross-sectional view of the plane at the tip apex, with a circularly-symmetric distribution of the $E$-field. The field was highly enhanced at the apex, and de-

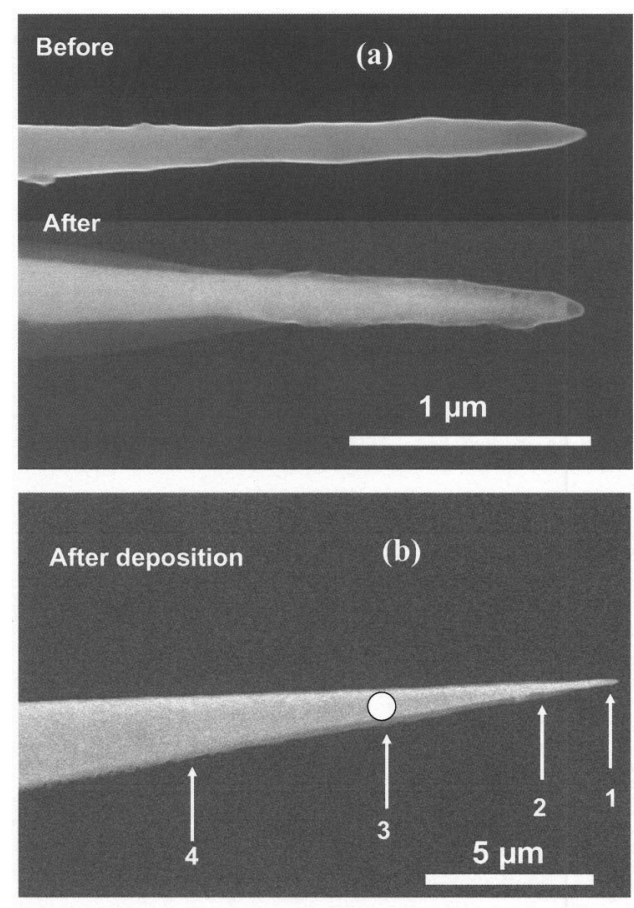

FIG. 3. (a) SEM micrographs of a W tip before and after laser irradiation; (b) an enlarged scope of view of (a). The labeled arrows indicate positions where micro-Raman spectra were taken for DLC films deposited on the W tip.

creased radially. The field distribution shown in Fig. 2 indicates that there is a shell of optical field surrounding the tip apex with a decrease in the intensity from the apex to the tip body. Since the UV laser decomposition of organic and hydrocarbon precursors is mainly photolytic, this shell of optical field surrounding the tip apex can be used for photolytic deposition of DLC films surrounding the tip apex. As shown by Lu $e t$ al. that at different laser fluences there are variations in phases of the deposited DLC films, ${ }^{7,8}$ an examination of the phases of the deposited films along the tips will show qualitative estimation of local optical field intensity and indicate whether the near-field effects are responsible to the DLC deposition.

SEM micrographs of a W tip before and after laser irradiation are shown in Fig. 3(a). During the laser deposition, the fluence was around $1250 \mathrm{~mJ} / \mathrm{cm}^{2}$. As shown in Fig. 3(a), the curvature radius of $\mathrm{W}$ tip before laser irradiation was around $20.4 \mathrm{~nm}$, aspect ratio (tangent of half-cone angle) around 4:1. The tip was first irradiated by one pulse. There was almost no change in the morphology. (The corresponding SEM micrograph is not shown here.) In contrast to the experiment of laser deposition in a benzene solution that a single pulse of laser can generate substantial DLC coatings, ${ }^{5}$ LCVD deposition may require more pulses and longer irradiation since the density of carbon feedstock is much lower in a precursor vapor than in a dense liquid solution. The same tip was then irradiated with 20 pulses at a frequency of $5 \mathrm{~Hz}$. A thin layer of coating was found, extending along the tip body. The curvature radius of the tip after deposition is around $25 \mathrm{~nm}$. A DLC film with an average thickness of $24 \mathrm{~nm}$ was found covering the first $1 \mu \mathrm{m}$ section of the tip. In Fig. 3(a), SEM micrographs also show that the coating extended to the tip body around $10-15 \mu \mathrm{m}$, with an average thickness around $60 \mathrm{~nm}$. 


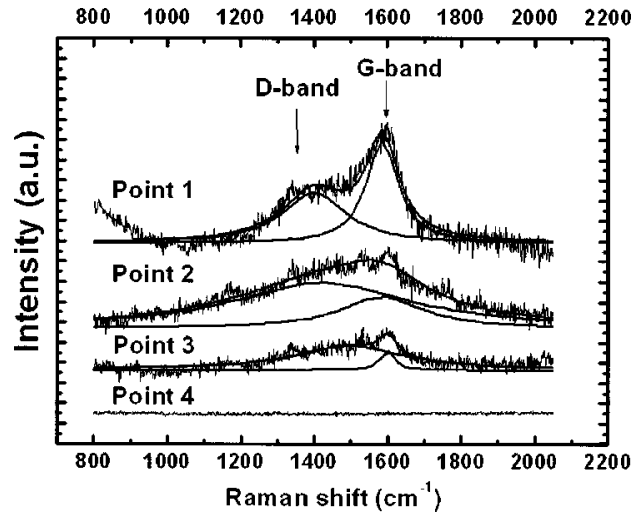

FIG. 4. Raman shift of the DLC films at different locations on the W tip shown in Fig. 3(c).

Raman spectroscopy was used to characterize the structure of the films along the tip apex. The arrows shown in Fig. 3(b) are the approximate positions where Raman spectra were obtained. The circular spot at point 3 denotes the argon laser beam spot during micro-Raman characterizations, which is $1 \mu \mathrm{m}$ in diameter. Figure 4 shows the Raman spectra of the DLC films at various positions along the tip. The spectra were Lorentzian fitted into $D$ - and $G$-bands. As indicated in Fig. 4, the structure of deposited films is DLC in nature and shows variations along the tip. $D$ - and $G$-bands are dominant at point 1 . At points 2 and 3, the two peaks overlap and merge into a broad peak. For point 4, the Raman spectroscopy shows only noise signals. In order to examine the structural properties of the film deposited on the back of the

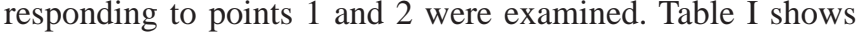
all the fitting parameters for spectra of DLC films along the W tip.

The Raman spectra of the DLC films are analyzed in terms of $G$ - and $D$-band positions, and integrated intensity ratio of the $G$ - and $D$-bands. ${ }^{10,11}$ As shown in the table, there are two important features that can be observed from points 1 (apex) to 4 (11 $\mu \mathrm{m}$ from the apex). First, $D$ - and $G$-bands have a monotonous blue shift. Second, the intensity ratio $I(D) / I(G)$ increases as the positions being further away from the apex. It was found that increasing the percentage of four fold coordination bonds leads to a decrease in both $G$ - and $D$-band frequencies instead of a mixture of the Raman peaks associated with diamond and graphite. ${ }^{9}$ Richlter ${ }^{10}$ calculated the frequency of the $G$-band using a simple valence force model weighted by the fraction of $s p^{3}$ and $s p^{2}$ bonds. They found that the frequency shifts in the $G$-band are caused only by changes in the force constants and correspond to a certain $s p^{3}$-bond fraction. The Raman shift of $D$-band towards lower wave number has been attributed to carbon atoms in $s p^{3}$ sites. Yoshikawa et al. ${ }^{11}$ have reported that the ratio of the $s p^{2}$ to $s p^{3}$ bonds in amorphous carbon films increase with the intensity ratio $I(D) / I(G)$. Therefore the simultaneous blue shifts in both $G$ - and $D$-bands together with an increase in the $I(D) / I(G)$ ratio suggest that the film is more diamondlike (higher $s p^{3} / s p^{2}$ ) at the apex. Along the tip apex to tip body, the films gradually become graphitic. The spectrum shows no DLC features when the position is more than $11 \mu \mathrm{m}$ away from the apex. In addition, as shown in Table I, the
TABLE I. Fitting parameters of Raman spectra at different positions along the tip, corresponding to the arrows shown in Fig. 3(c). Note that points b1 and $\mathrm{b} 2$ correspond to the positions on the back of the tip which are 1.5 and $4 \mu \mathrm{m}$ away from the apex.

\begin{tabular}{ccccc}
\hline \hline & & \multicolumn{2}{c}{ Raman peak position } & \\
\cline { 3 - 4 } Point & $\begin{array}{c}\text { Distance from } \\
\text { apex }(\mu \mathrm{m})\end{array}$ & $D$-band $\left(\mathrm{cm}^{-1}\right)$ & $G$-band $\left(\mathrm{cm}^{-1}\right)$ & $I(D) / I(G)$ \\
\hline 1 & 1.5 & 1400.7 & 1586 & 1.01 \\
2 & 4 & 1422.6 & 1586.1 & 3.09 \\
3 & 7 & 1485.9 & 1600.7 & 7.52 \\
4 & 11 & $\ldots$ & $\ldots$ & $\ldots$ \\
b1 & 1.5 & 1393.9 & 1596.6 & 0.87 \\
b2 & 4 & 1416.8 & 1599.1 & 0.89 \\
\hline \hline
\end{tabular}

quality of DLC on the back of the tip also shows that the positions of $G$ - and $D$-bands have a blue shift from points b1 to b2. The $I(D) / I(G)$ are 0.87 and 0.89 , respectively. This indicates that there are substantial $s p^{3}$ species deposited on the back of the tip close to the apex. Generally, there will be no deposition on a bulk substrate if there is no direct laser irradiation. The phase-graded DLC coated on both sides of the tip at the apex suggests that there was local field surrounding the tip. This is in agreement with the simulation results and hence again confirmed that the deposition was induced by the near-field effects resulted from the interaction between the laser and the $\mathrm{W}$ tip.

In summary, DLC films were deposited on $\mathrm{W}$ tips under $\mathrm{KrF}$ excimer laser in a LCVD chamber. Micro-Raman spectroscopy showed a phase-graded deposition of DLC along

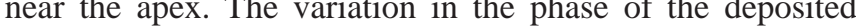
DLC films suggests a corresponding variation in the local optical intensity along the tips. This conclusion is in agreement with the simulation results suggesting that there was an optical near field gradient from tip apexes to tip bodies. Hence, local optical-near-field-induced deposition was directly confirmed.

The authors would like to thank Nebraska Research Initiative, NSF MRSEC at University of Nebraska-Lincoln, and Research Foundation for Opto-Science and Technology (Japan) for financially supporting this research work.

${ }^{1}$ J. Wessel, J. Opt. Soc. Am. B 2, 1538 (1985).

${ }^{2}$ U. C. Fischer and D. W. Pohl, Phys. Rev. Lett. 62, 458 (1989).

${ }^{3}$ Y. F. Lu, Z. H. Mai, G. Qiu, and W. K. Chim, Appl. Phys. Lett. 75, 2359 (1999).

${ }^{4}$ L. Novotny, R. X. Bian, and X. S. Xie, Phys. Rev. Lett. 79, 645 (1997).

${ }^{5}$ J. Shi, Y. F. Lu, R. S. Cherukuri, K. K. Mendu, D. W. Doerr, D. R. Alexander, L. P. Li, and X. Y. Chen, Appl. Phys. Lett. 85, 1009 (2004).

${ }^{6}$ J. P. Ibe, P. P. Bey Jr., S. L. Brandow, R. A. Brizzolara, N. A. Burnham, D. P. Dilella, K. P. Lee, C. R. K. Marrian, and R. J. Colton, J. Vac. Sci. Technol. A 8, 3570 (1990).

${ }^{7}$ Y. F. Lu, S. M. Huang, X. B. Wang, and Z. X. Shen, Appl. Phys. A: Mater. Sci. Process. 66, 543 (1998).

${ }^{8}$ Y. F. Lu, S. M. Huang, C. H. A. Huan, and X. F. Luo, Appl. Phys. A: Mater. Sci. Process. 68, 647 (1999).

${ }^{9}$ D. Beeman, J. Silverman, R. Lynds, and M. R. Anderson, Phys. Rev. B 30, 870 (1984).

${ }^{10}$ A. Richter, H-J. Scheibe, W. Pompe, K-W. Brzezinka, and I. Muhling, J. Non-Cryst. Solids 88, 131 (1986).

${ }^{11}$ M. Yoshikawa, G. Katagiri, H. Ishida, and A. Ishitani, J. Appl. Phys. 64, 6464 (1988). 